\title{
Study on the Evolution of Piano Playing Techniques
}

\author{
Yiyu Zhu
}

University of Sanya, Sanya, Hainan, 572022

\author{
Keywords: Piano, Playing Techniques, Evolution Method
}

\begin{abstract}
The technique of piano playing is an important index to measure the technical level of the piano and also the condition basis for the piano playing to embody different styles. Piano playing is the main means of expressing emotions during the romantic period. By playing different techniques, cultivating people's sentiments and souls, The development of piano performance in the period was summarized, and the evolution of the piano playing technique was deeply analyzed.
\end{abstract}

\section{Introduction}

The period of romanticism is the period of catharsis of emotions, which is very different from the classicalism of the past and focuses on the bold expression of his feelings. In music, pianists fully express their emotions, interests and talents by playing. Piano as the most mainstream expression of music at the time, loved by many literary enthusiasts, and piano techniques also developed vigorously during this period, evolving, piano playing techniques to a new level.

In the early 19th century, classicism and romanticism came across unexpectedly. Two distinct artistic styles formed the two major genres at the time. Piano playing as the main tool of catharsis was very popular at that time, forming a unique style. In the late classical music, vaguely romantic atmosphere can feel. Famous musicians Beethoven and Rossini and others like to join the romantic elements when making music, so they can be regarded as the pioneer of romantic music. In the middle of the 19th century, the romantic style of music was officially popularized, forming a distinctive musical style of the time. Subsequently, the birth of the master of romantic music--Schubert, whose representative works are "devil", "Rose", "Madonna" and so on.

The so-called piano technique is to play the piano skills and techniques, through the mastery of skills and skills, the music will be given to the unique soul, play moving song. There are four main piano techniques, namely tremolo, octave, legato and scraping. In the romantic period, the most widely used technique is octave. This technique requires a high degree of performer, must have three requirements, followed by finger strength, wrist strength and arm span. Only the perfect combination of these three factors, can we use the octave handy. With the vigorous development of romantic music, the scraping technique has gradually entered people's eyes and has been developed to a certain extent. Thus, in the period of romanticism, the technique of piano was at a stage of evolution and evolution. The techniques of mutual penetration and influence each other presented a diversified stage of development.

\section{Modern Piano Development and Improvement}

Modern piano has experienced a long period of development, from the earliest organ to string keyboard instrument has gone through thousands of years. From the ancient piano to the piano, even in the instrument itself more than 150 years of development and updating of the instrument, but also a hundred schools of thought, resulting in many different shapes and branches. Unlike current technology products, the replacement of old and new musical instruments is not a quick vertical replacement, not that the rear piano is more advanced. In general, the piano produced at a given time and place is definitely suitable for playing that time And the place's work. In this process, the performance of the keyboard instrument is slowly transition from the old musical instrument to a new musical instrument to adapt to changes in the development of the piano performance in the early largely rely on the improvement and development of musical instruments, and composers 
creative approach The continuous innovation and the increasing difficulty of playing technique also put forward higher requirements for the piano makers of the piano makers. It can be said that the development and evolution of the technique of the piano has a mutual promotion and influence with the development and evolution of the piano itself Close time

After nearly a hundred years of development, the piano has been very different from the early piano, the main changes and reforms are reflected in the linkage mechanism and the production of materials. The piano form has been basically established in the romantic period. The grand piano of this period lays an important material foundation for the composer's creation and playing technique. The musical instrument, as the fundamental of the existence of technique, also makes great changes in the piano during the romantic period. And the early piano has made a big difference. In romantic times, there are more and more people learning the piano, but the excessive size of a grand piano limits its popularization as a home-use piano. Therefore, it is more and more important that a small piano occupy a small space and be comparable to grand piano functions. Although upright pianos have a comparable performance to grand pianos, their mechanics are quite different, especially the mechanism of soft pedal, which leads to some differences in performance. Therefore, romantic composers Or choose to use the grand piano for their creation and performance. Although some playing techniques can not achieve the perfect effect on a grand piano in a vertical piano, this does not prevent the development and evolution of the piano technique. The upright piano has made indelible contributions to the modern piano teaching and popularization contribution.

\section{Piano Performance Evolution Analysis}

Piano music reached an all-round development during the romantic period. At this time, the piano has been continuously improved in terms of structure and performance. It can be said that the piano was close to the modern level. As the piano popular among the princes and grandchildren gradually moved to the stage of the theater, the pianist appeared in front of the general public as the theater's "performance figure." Piano playing was gradually stimulated by the outside world. , From wrist to arm, and even affect the player's entire upper body. Romantic period piano music is different from the classical period, in the creative thinking and the use of music material has a tremendous change, promoting the playing field of high technology, at the same time Chopin singing of piano music and Liszt's piano orchestra Team processing and other deep exploration of the performance of the piano, triggering a revolution in the pianist performance skills.

Chopin with superb touch technology, the delicate sound changes, the color of the pedal application and the reasonable speed of the free and subtle treatment, the piano's inner expression to play most vividly. In Chopin's performance method, its means of fingering is more unique, breaking the traditional rules and regulations, the use of large fingering black keys, the thumb drilled from the little finger, the same finger sliding from the black key to the white or white key to the white key . Based on his predecessors, Liszt further explored the performance of the piano and formed a unique set of skills. Such as the exact octave, polyphonic big jump, fast third, sixth, octave after sentence, octave hands staggered octave (ie, "Liszt octave"), fast wheel fingers, rapid decorative high notes and other groups . Liszt playing, often carrying his hand and arm high, the body movements are also great, the pursuit of the use of the greatest instantaneous force played a bold, loud strum, the pursuit of symphonic sound colors. Brahms played the extreme extension of the fingers on the piano, and the little finger crossed new techniques such as thumbs and jumpers to take the piano performance one step further.

As a master who deeply explored the performance potential of piano, Liszt's handling effect on the piano band and the demanding skill requirements of his works triggered a radical revolution in the overall playing skills of the pianist when playing the piano Rely on finger technology has been very difficult to perfectly play this period of piano music, which requires the player's arms, shoulders, torso, etc., all played with the muscles associated with coordination. Each movement of a finger has its own motion related to the entire arm. For each of the chords and long-jumps that perform more vigorously, the player is required to find a suitable posture and a special fingering, and each change in tempo and intensity Echoes with the inner rhythm. 
In the early 19th century, when the "finger school" continued to teach students with their disciplined teaching methods, restless factors also appeared in their students. These students generally have a musical talent, they do not listen to the so-called "tradition" and "experience", these gifted students, think about thinking, they will find their own way to practice, and sometimes and his mentor There are mutually antagonistic situation. These big-minded students who have their own intuition and have their own ideas, they can abandon the shackles of the old school, in thinking and trying, they will find that aside the shackles of the fingers, with arm strength, join Co-ordination of the body, skills can be improved. Therefore, they are becoming more and more broadly mastered. When these students become masters, they begin teaching their students with new, progressive ideas. Chopin, a "piano poet", does not like to teach piano classes, even though he seldom studies piano education. However, some of his teaching ideas are very unique. He believes in the importance of hands, wrists, and the whole arm. He views the entire upper limb as an integral whole. When playing a melody with a larger span or scale, it is recommended that the arm move along the keyboard as the hand moves. He teaches a variety of different touch ways and playing methods and is reflected in his works, perhaps related to the personal style of work. Chopin pays special attention to the singing and playing of legato and playing. He advises students to study on the piano Singing, the performer should listen to the singing of the best singer and even try to sing and comprehend the music himself. Robert Schumann believes that the ability of a person to "hear" one's own performance is a player's ability. He suggested that the performer, first of all, should understand and understand the essence of listening to a piece of work instead of tearing it off like a mechanical one. Schumann once wrote: "Your fingers need to follow the will of the brain and can not do the opposite." "Do not bounce it until you can not hear (can not understand) your music." According to Liszt , "Tips do not need to practice, but need to rely on the skills of practice" "Through the analysis of skills, after listening to the difficulties of music into some basic forms, mastered the ability of the performer, also have played for this instrument The ability to write any work. "

And these masters of teaching ideas and methods in the 20th century developed into a primary "applied psychology school" was spread and promotion. However, the use of "auditory" can not be neglected in the training of musical expression. All the music works, its ultimate goal is to meet people's aesthetic needs, and for the music works, the aesthetic needs of the satisfaction must be achieved through hearing, no matter how good each player's skill superb, playing speed How fast, if he is not music, difficult to express the musical content of a musical work, then he is not a full player. Especially in the later period of romantic period, in the works of French Impressionism, the requirements for timbre are getting higher and higher. At this moment, in the training of piano, it is necessary to join auditory training. After the performer masters a certain playing technique, Those who need to use a lot of hearing, whether it is the first auditory visual or direct sound feedback, to work together to guide the way to adjust the performance of touch keys, touch keys to change the intensity of playing.

\section{Conclusion}

In the modern era, it may be hard to find a type of piano teaching similar to the "finger school" with representative lines. These past teaching ideas and trends have evolved into today's modern piano teaching. They have not been fixed yet School of teaching. Piano teachers based on previous research results of targeted teaching and training, and more and more emphasis on the piano's ability to synthesize. Although the practice of basic performance techniques was initially established and emphasized the importance of exercises, it did not mean to carry out the boring training of the "finger school" blindly. At the same time, the teaching of "Anatomy and Physiology" was added Research results, to alleviate the fatigue caused by playing. For the "Applied Psychology School" in the use of hearing, but also from the beginning into the teaching, teaching piano comprehensive training. At the same time, some progresses in the theory of music teaching and the compilation and use of new piano teaching materials have also played a positive role in the basic teaching of the piano, making piano learning less mechanical, dull and tasteless, piano teaching and 
piano. The training of playing techniques has entered a new stage of all-round development.

\section{References}

[1] Zhou Guangren Piano Art Center Opens New Piano Educational Age [J]. Musical Instruments 2017 (07)

[2] Wang Jiao Qiao. University of piano education and rational reflection of the teaching model [J]. China Hi-tech Zone. 2017 (19)

[3] MA Ling. My opinion about adult piano teaching [J] .Journal of Liaoning Institute of Science and Technology. 2017 (04)

[4] Chen Weiping. Multi-point into the optimization of college piano teaching strategies [J]. University Education. 2017 (09)

[5] Yan Xinzhen. Analysis of the importance of children's piano primary textbook [J]. Art Evaluation. 2017 (16)

[6] He Shujin, Bu Li. Research on the Piano Teaching Reform and Innovation in Chinese Universities [J]. Contemporary Music. 2017 (18)

[7] Mao Yu. Piano Teaching Research in Colleges and Universities from the Perspective of Aesthetic Education [J]. The Voice of the Yellow River. 2017 (12) 